\title{
Enhancing capacities of riparian professionals to address and resolve transboundary issues in international river basins: experiences from the Lower Mekong River Basin
}

\author{
W. Douven ${ }^{1}$, M. L. Mul ${ }^{1}$, B. Fernández-Álvarez ${ }^{1}$, S. Lam Hung ${ }^{2}$, N. Bakker ${ }^{2}$, G. Radosevich ${ }^{3}$, and P. van der Zaag Za $^{1,4}$ \\ ${ }^{1}$ UNESCO-IHE Institute for Water Education, P.O. Box 3015, 2601 DA Delft, The Netherlands \\ ${ }^{2}$ Mekong River Commission, Regional Flood Management and Mitigation Centre, P.O. Box 623, \# 576, National Road 2, \\ Chak Angre Krom, Meanchey, Phnom Penh, Cambodia \\ ${ }^{3}$ Rado International, VP Tower Suite 1127, 21/45 Chawakun Rangnam Road, Bangkok 10400, Thailand \\ ${ }^{4}$ Delft University of Technology Faculty of Civil Engineering and Geosciences, P.O. Box 5048, \\ 2600 GA Delft, The Netherlands
}

Correspondence to: W. J. M. Douven (w.douven@unesco-ihe.org)

Received: 26 February 2012 - Published in Hydrol. Earth Syst. Sci. Discuss.: 26 March 2012

Revised: 12 July 2012 - Accepted: 18 August 2012 - Published: 7 September 2012

\begin{abstract}
This paper analyses the design and impact of capacity building programmes aimed at enhancing capacities of riparian professionals to address and resolve transboundary issues in international river basins. The case study is a programme developed by the Mekong River Commission (MRC). A post-training evaluation was applied to assess its impact in terms of individual capacity enhancement and change (use and application of knowledge, factors hampering application, and change in function and opportunities within the organisation). The design of the Capacity Building Programme of the MRC Flood Management and Mitigation Programme required a well balanced range of subjects (such as IWRM (integrated water resources management), model and decision support systems, and international water law). The post-training evaluation, 6 months after the last training workshop, showed an increase in familiarity with the topics for all 37 respondents, with the highest increase for the respondents with few years of working experience and from training and education institutions. The relevance of the subjects taught was highlighted by $95 \%$ of the respondents, and $78 \%$ of the participants had already used some of the acquired knowledge in their job. The respondents indicated that they did not have sufficient opportunities to apply all knowledge. The phased implementation and training of lecturers during the training workshops had a good impact, directly through increasing involvement in facilitation and delivery
\end{abstract}

of the capacity building programme and through the use of the knowledge gained in short courses and development of curricula at their institute. For these types of capacity building programmes, a few recommendations can be made. The selection of participants is crucial for the application of the learned knowledge in their work. The integrative nature of transboundary water issues calls for a capacity building programme addressing a wide range of subjects, which can be understood by a wide range of professionals from different sectors. Training methods should also address this integrative nature through, e.g. roleplays and case studies. A successful capacity building programme needs to address the three levels of capacity building (enabling environment, organisations, and individual staff) and involve national and regional training and education institutes.

\section{Introduction}

Adequate capacity of riparian countries to address transboundary issues in river basins is an important condition for successful river basin management (UNESCO-WWAP, 2006). An important element of this capacity is awareness and recognition of upstream-downstream interdependencies, as water users in a river basin are linked through the flow of water. These water links or water dependencies are 
frequently seen as a potential problem when upstream developments have negative downstream consequences. However, certain interventions in upstream tributaries which have positive downstream impacts may not be economically feasible if considering only the direct benefits. Successful transboundary river basin management therefore includes basin wide optimisation of benefits. At the same time, environmental considerations are often not taken into account. As a result, differences may emerge between water users in different parts of a river basin. This is especially true in transboundary river basins where water has created links between riparian countries. A solution to this potential problem is that the countries, sectors and water users involved should become aware and recognise the upstream-downstream interdependencies that inevitably exist, and find ways of institutionalising them. Institutionalising interdependencies will strengthen the ties between riparian water users, and such intensified social and economic cooperation may boost economic development regionally (Chheang, 2010). At the same time, transboundary agreements do not always consider the local situation and may accelerate ecological degradation and increase the risk to human security (Fox and Sneddon, 2007). To balance these challenges, the "from potential conflict to cooperation potential" (PCCP) movement ${ }^{1}$ was initiated (UNESCO, 2003). Its success hinges on societies and citizens being well-informed and aware of the interdependencies related to water.

The Mekong River Basin is one of the longest rivers worldwide. The river crosses parts of China's Yunnan Province, Myanmar, Lao PDR, Thailand, Cambodia and Vietnam. The population in the Lower Mekong Basin (Cambodia, Lao PDR, Thailand and Vietnam) is around 60 million, is relatively young (around $25 \%$ between 0 and $14 \mathrm{yr}$ old), and is largely living in rural areas (75\%) (MRC, 2010). The Mekong River and its resources provide essential benefits for the Mekong population, in particular those living in rural areas, and the total direct-use value of fishery resources has been estimated at about US\$2 billion per year (Baran et al., 2007). The benefits are strongly related to the yearly recurrent flood phenomenon (Sneddon and Fox, 2006). The fluvial and floodplain habitats in the Mekong Plain form critical feeding and breeding habitats for over 700 fish species, of which some migrate seasonally between the lower and upper regions of the Mekong Basin (Poulsen et al., 2002). Although normal floods bring many benefits, large floods can be devastating and cause a lot of casualties and damage like the 2000 floods and the recent 2011 floods (MRCFMMP, 2009a, 2011). The average annual flood damage for the Lower Mekong basin is estimated to be US\$60-70 million per year and is mainly concentrated in Vietnam and

\footnotetext{
${ }^{1} \mathrm{PCCP}$ is one of UNESCO International Hydrological Programme's (IHP) contributions to the United Nations' World Water Assessment Programme (WWAP). http://www.unesco.org/new/en/ natural-sciences/environment/water/ihp/ihp-programmes/pccp/.
}

Cambodia (MRC-FMMP, 2009a). Droughts in the basin, unlike floods, can occur at any time of the year and only have negative impacts. Due to climate change, floods and droughts are expected to become more extreme in the future (MRC, 2010). In addition, infrastructural developments affect the flow regime of the river with both positive and negative impacts.

The Lower Mekong Basin countries are all "medium human development" countries (human development index between 0.500 and 0.799 ) and show gradual improvement in development (MRC, 2010). Currently, the basin still is one of the last great rivers without large reservoirs build in the middle and lower parts of the mainstream. Future river basin developments will impact to various degrees the river system and its functions. Preventing, addressing and resolving related transboundary issues requires cooperation in the Mekong River Basin. The Mekong Agreement 1995 between Cambodia, Lao PDR, Thailand and Vietnam aims at providing an effective framework for such cooperation, and the transboundary dimension is at the core of the Mekong Agreement 1995 (MRC, 1995). The Mekong River Commission, established by the Mekong Agreement, aims to facilitate cooperation on the development and the management of the water and environmental resources of the Lower Mekong River Basin (MRC, 1995). Although the Mekong Agreement 1995 is one of the world's first agreements which considers equitable utilization and considers the protection of water quality, it faces many challenges (Bearden, 2010). These challenges include the fact that the two upstream countries, China and Myanmar, are not part of the MRC and have not signed the agreement. For the four member countries, there is insufficient capacity to implement the Mekong Agreement 1995.

Now 15 yr after the Mekong Agreement 1995 was signed, the first major dam proposal on the mainstream (Xayaburi dam in Lao PDR) is under discussion by the four downstream countries (MRC, 2011). The Procedures for Notification and Prior Consultation and Agreement (PNPCA) under the Mekong Agreement 1995 are being applied to address and resolve the transboundary issues (MRC, 2003). Currently, capacity in riparian countries is limited and shows regional variation in implementing such procedures, adequately understanding and analysing the implications of these developments, and coming to common agreements on such developments. Therefore, one of the components of the Flood Mitigation and Management Programme (FMMP) of the Mekong River Commission aims at enhancing the cooperation between member countries through building skills and strengthening knowledge and capacities. To achieve this goal, the MRC-FMMP initiated a capacity building programme aimed at strengthening the capacity of both riparian high-level decision-makers and mid-level professionals on anticipating and resolving transboundary flood issues in the Lower Mekong River Basin (MRC-FMMP, 2008; Douven et al., 2007). The programme was implemented in two phases from 2009 until 2011. During these two phases, 76 mid-level 
professionals from national governmental institutes ${ }^{2}$, including 12 lecturers from national and regional training and education institutes, were trained. An exchange visit was organised for high-level decision makers ${ }^{3}$ during phase 1.

In this paper, we analyse the design and impact of capacity building programmes in water and flood management in a transboundary context and try to learn some general lessons. This is done by studying the example of the MRC-FMMP Capacity Building Programme in detail. We present the design of the MRC-FMMP Capacity Building Programme and analyse its impacts in terms of individual capacity enhancement and change using a post-training evaluation. Based on the insights gained, we give recommendations for the design of similar programmes addressing cooperation in transboundary rivers. The paper is organised as follows. Section 2 presents the theoretical framework consisting of capacity building and its key elements, as well as impacts of capacity building programmes. Section 3 gives information on the methodology that was used which relates to the design of the MRC-FMMP Capacity Building Programme and the post-training evaluation. The post-training evaluation results of the MRC-FMMP Capacity Building Programme are presented and discussed in Sect. 4. Finally, Sect. 5 contains the conclusions and recommendations for capacity building programmes in support of cooperation in transboundary rivers.

\section{Enhancing human capacities to address transboundary water related issues}

\subsection{Capacity requirements for addressing transboundary water related issues}

A key element in institutional arrangements in international river basins is the need to manage river basins as a whole and recognise the upstream-downstream interdependencies. To achieve this, far-reaching capacities are needed which are often lacking (UNESCO-WWAP, 2006). Capacity is a broad term and used in different contexts (see Box 1). These specific definitions illustrate some common elements which we will take into consideration when discussing capacity. One common element is that capacity relates to abilities: abilities to perform functions (UNDP, 2008), abilities to manage successfully (OECD-DAC, 2006), and abilities to function strategically and autonomously (Kaplan, 2007). Another common element is that abilities are linked to conditions at different levels. These levels are an appropriate policy and legal framework (the enabling environment), effective, flexible and adaptive organisations (institutional or organisational capacity), and adequate individual capacities (human

\footnotetext{
${ }^{2}$ Professionals from ministries like hydrology and water resources, environment and foreign affairs, national research institutes and National Mekong Committees.

${ }^{3}$ Ministers, Director Generals, Joint Committee members and Chairmen of National Mekong Commitees.
}

resources) (Alaerts and Kasperma, 2009). We will address the level of individual capacity building specifically, as it is the focus of this paper.

Individual capacities (for a certain function) can be expressed in terms of professional competencies. Various authors have distinguished different categories of professional competence. Cheetham and Chivers (1996), for instance, distinguish between knowledge/cognitive competence (e.g. theoretical/technical knowledge, tacit knowledge, procedural knowledge of finances or projects), functional competence (e.g. occupation-specific skills like report writing, IT literacy, budgeting, project management), personal or behavioural competence (e.g. self-confidence, control of emotions, listening, objectivity, collegiality, sensitivity to peers, etc.), and values/ethical competence (e.g. adherence to laws, social/moral sensitivity, confidentiality, etc.). Different functions will require different combinations of competencies (Cheetham and Chivers, 1996; Uhlenbrook and de Jong, 2012). A floodplain modeller for instance will require a strong focus on technical knowledge/cognitive competencies. A water manager involved in addressing transboundary issues in river basins will require more integrative knowledge/cognitive competencies in combination with a strong focus on personal and value/ethical competencies.

New water managers will need to be trained and educated addressing these mixed competence profiles. This is shown by Savenije and Hoekstra (2003), who describe the evolution of the field of integrated water resources management (IWRM). This field evolved from an engineering approach (water resources development) to water resources management (recognising that water can be "overexploited" and accounting for ecological and social constraints) to IWRM, in which water management is embedded in an overall policy for socio-economic development, physical planning and environmental protection. Savenije and Hoekstra (2003) argue that new water managers should be able to design and facilitate the process of IWRM: identify water-related problems early on (and analyse causes), carefully define the problem, understand the interests of those involved and/or affected by it and its solution, design the process towards solving the problem, and facilitate that process and bring it to a satisfactory conclusion (van der Zaag et al., 2003). Programmes educating these new water managers will need to address a mix of knowledge areas and skills which are related to technical aspects that enhance the understanding of physical, biological and other technical processes; non-technical aspects that enhance the understanding of legal, social, economic, financial, institutional and managerial aspects; and integrative aspects that enhance the understanding of the interplay between technical and non-technical aspects (e.g. WaterNet IWRM MSc Programme, see Jonker et al., 2012).

Similar capacity building programmes have been developed globally and implemented in the region. For example, the Transboundary Water Management programme (Earle et al., 2008) covers topics such as negotiation tactics, 
- The process through which individuals, organizations and societies obtain, strengthen and maintain the capabilities to set and achieve their own development objectives over time (UNDP, 2008: 4).

- Capacity is the ability of people, organisations and society as a whole to manage their affairs successfully (OECD-DAC Network on Governance, 2006: 7).

- Capacity is the ability of an organisation to function as a resilient, strategic and autonomous entity (Kaplan, 2007).

- Capacity is that emergent combination of individual competencies, collective capabilities, assets and relationships that enables a human system to create value (Baser and Morgan, 2008).

Box 1. Capacity development definitions.

stakeholder participation, hydropolitics, environmental water requirements and benefit sharing; however, it does not address the biophysical aspects of the river basin. An international team of experts executes this training programme. On the other hand, Cap-Net, a global network for capacity building for sustainable water resources management, emphases the importance of local ownership and partnership for capacity building (Cap-Net, 2002). Their training materials on various aspects of integrated water resources management are online available and can be used for trainings locally (http://www.cap-net.org/). The MRC Integrated Capacity Building Programme "aims to build the capacities required for the MRC to achieve its mandate as set out in the Mekong Agreement 1995" (MRC, 2009). This programme coordinates all capacity building activities within the MRC. However, many other MRC programmes ${ }^{4}$ have their own capacity building components. This paper describes the capacity building component of the MRC Flood Management and Mitigation Programme.

\subsection{Impact of capacity building programmes}

Baser and Morgan (2008) have analysed the interrelation between capacity, change and performance, in particular at the individual staff level. They argue that the interrelations between capacity, change and performance are complex and need to be seen in relationship to the socio-political dynamics of the context within which they take place, including external context, stakeholders, external interventions, and internal features and resources. Also Mizrahi (2004) addresses the difficulties in measuring capacity enhancement and concludes - amongst others - that capacity enhancement involves more than strengthening individual capacities. This is in line with Alaerts and Kaspersma (2009), who argue that the combination of different levels of capacity - institutional,

\footnotetext{
${ }^{4}$ See http://www.mrcmekong.org/about-the-mrc/programmes/ for more information about all MRC programmes.
}

organisational and individual staff - is a prerequisite for a successful programme. In this respect, "adaptive capacity" is also seen as a key capability at different levels, and it entails learning from past experiences and hence better coping with existing and future challenges (Pahl-Wostl et al., 2007). Mizrahi (2004) also concludes that capacity enhancement should be regarded as a process, capacity enhancement indicators should be related to development objectives and specific actors towards which a project is directed, and capacity enhancement projects must entail local ownership.

\section{Methods: implementation and evaluation of the MRC-FMMP Capacity Building Programme}

\subsection{Design of the MRC-FMMP Capacity Building Programme}

Processes of identifying, addressing and resolving transboundary water and water-related issues often have interdisciplinary dimensions, and are carried out by teams involving members with technical as well as administrative backgrounds working at different governmental agencies. A programme, like the MRC-FMMP Capacity Building Programme, which targets these professionals will need to address physical, legal, technical, social, economic and political aspects in order to be able to educate professionals with specific backgrounds as team members who understand each other's background and can work in multi-disciplinary teams.

The design of the MRC-FMMP Capacity Building Programme has been based on the training needs of the four MRC member countries, which were identified in several national consultation meetings (MRC-FMMP, 2008). Also, consultations were held with other MRC programmes to ensure adequate integration with these programmes. Reports of the FMMP on transboundary flood issues and the legal aspects of the Mekong Agreement 1995 aimed at enhancing cooperation in addressing these issues were consulted, and 
helped in outlining the new capacity building programme within the scope of the subject (MRC-FMMP, 2007, 2009b).

The overall objective of the MRC-FMMP Capacity Building Programme is to enhance the capacity of riparian decision-makers and mid-level professionals in anticipating and resolving transboundary flood issues, differences, and disputes in the Lower Mekong River Basin (MRC-FMMP, 2008). Compared to the levels of capacity building addressed in Sect. 2, the programme targets the third level - individual capacities - specifically. In the first phase, decision-makers also participated, with the intention - in the long term - to induce changes in the way organisations function, and therefore the programme, indirectly, also targeted the second level of capacity - organisational capacity. In this paper, however, we will present the part of the programme developed for the mid-level professionals only.

The MRC-FMMP Capacity Building Programme was developed in 2 phases (Phase 1 in 2009 and Phase 2 in 2010 and 2011), which allowed for a gradual development of the curriculum and related training materials based on regular evaluations. A key element in the design of the MRC-FMMP Capacity Building Programme was the involvement of national and regional training and education institutes ${ }^{5}$. The same group of lecturers from these training and education institutes participated in both phases to strengthen their knowledge and skills, with the idea in mind that in later phases they could take over implementation of at least part of the MRC-FMMP Capacity Building Programme at the national level. A post-training evaluation (after Phase 2) was carried out to assess the impact of the MRC-FMMP Capacity Building Programme in terms of the individual capacity enhancement of the mid-level professionals and how it changed their working situation. Related to Baser and Morgan's (2008) (Sect. 2) model, we address in this paper aspects of capacity and change, and not performance.

\subsection{Learning objectives and curriculum of the MRC-FMMP Capacity Building Programme}

The specific learning objectives for the mid-level professionals participating in the MRC-FMMP Capacity Building Programme are strongly related to those identified for the new water managers (Sect. 2). Participants at the end of the programme were expected to be able (MRC-FMMP, 2008):

- To describe the key characteristics and challenges of the Mekong system, describe the key transboundary issues, and the rights, interests and responsibilities of those involved and/or affected by it and its solution.

\footnotetext{
${ }^{5}$ Royal University of Phnom Penh, Phnom Penh, Cambodia; National University of Laos, Vientiane, Lao PDR; the Mekong Institute, Khon Kaen, Thailand; King Prajadhipok's Institute, Bangkok, Thailand; and the Water Resources University, Hanoi and Ho Chi Minh City, Vietnam.
}

- To contribute to/facilitate the process of addressing and resolving transboundary issues in line with options provided in the Mekong Agreement 1995.

- To be aware of the available tools (engineering, environmental, economic, conflict prevention and management) in supporting the process of addressing and resolving transboundary issues.

- To critically review the process of addressing and resolving transboundary issues, the role of MRC institutions, the role of technical tools, and the conditions needed for implementation.

The MRC-FMMP Capacity Building Programme consisted of three training workshops and a role play aimed at building the right mix of knowledge and skills to address transboundary flood issues. The four main knowledge areas targeted were (i) "Introduction Mekong", giving an introduction about the Mekong river system, its transboundary floods, and concepts of IWRM and integrated flood risk management, (ii) the "Mekong Agreement 1995", describing the main features of the agreement and its procedures in addressing and resolving transboundary issues, (iii) "Conflict management approaches", highlighting the type of approaches available including alternative dispute resolution (ADR), and (iv) "Technical tools", addressing the importance of tools like GIS, models and decision support systems in providing adequate information in the process of addressing and resolving transboundary issues. Table 1 presents the four knowledge areas targeted, including the subjects taught in each of the training modules. The table also highlights the type of teaching methods used in each of the modules. The variety of teaching methods, a mixture of lectures, case studies and assignments in combination with a diverse group of participants, not only addresses the knowledge and functional competencies, but also the value/ethical competence as described in Sect. 2.1. The participants become more aware and sensitive to the issues at play throughout the basin through the interaction with fellow participants. The programme was designed over a nine month period, in which the participants were expected to attend all training modules. This design was based on the idea of incremental learning and to ensure that the knowledge gained would take root and would be sustained. It was also expected to instil self-confidence as well as respect and trust among the participants as they participated in the programme as a group. At the end of the programme, newly introduced in the second phase, the participants participated in the so-called Pilot Study (MRC-FMMP, 2012). The Pilot Study is a role play lasting three days in which the participants - representing the different countries and MRC institutions - were asked to address and resolve a given imaginary transboundary issue (e.g. a proposed hydropower development) following the basic principles of the Mekong Agreement 1995 and supported by a set of technical tools and conflict management tools (Fig. 1). This Pilot 


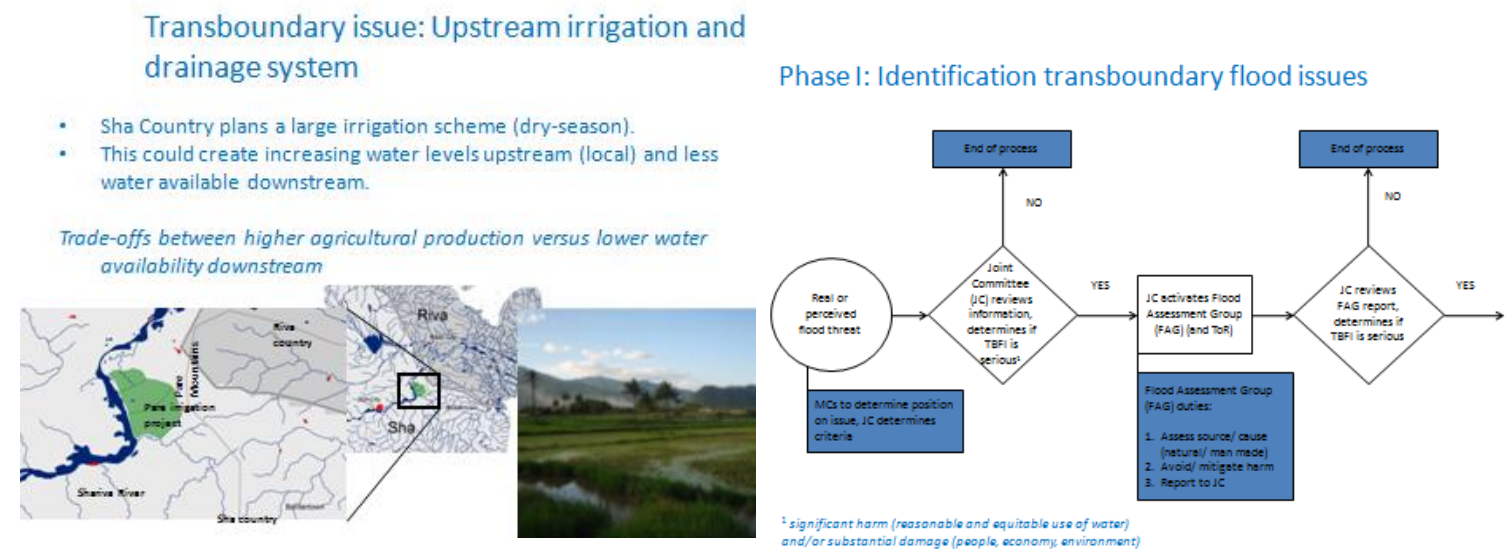

Shariva Computer Simulation Tool
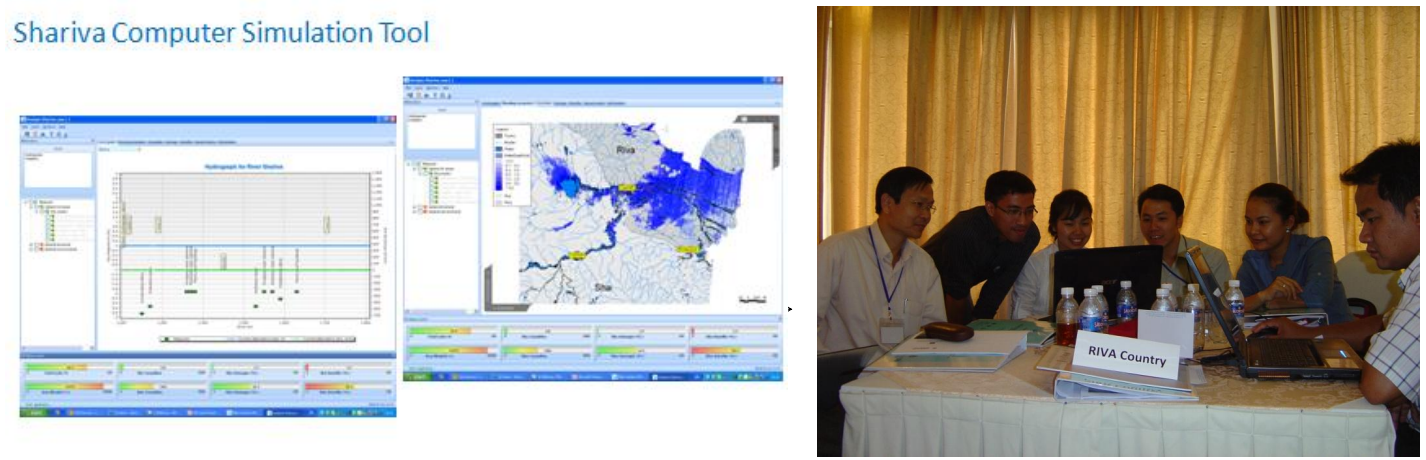

Fig. 1. Pilot Study on addressing and resolving a transboundary issue. Top left: the imaginary transboundary issue, top right: the process of addressing the issue and mandate of institutions (in line with the Mekong Agreement 1995), bottom left: an example of a tool to support the process, and bottom right: simulated negotiations between parties taking place.

Study was introduced to allow the participants to apply and reflect upon the knowledge gained and skills acquired during the nine month programme period.

\subsection{Measuring impacts: post-training evaluation}

A post-training survey was carried out to assess the training outcomes and impacts in the medium term. The aim was to assess what people had done with their (expected) enhanced capacities beyond simply assessing whether they have retained the theory, which in general is a very limited part of capacity enhancement (Kirkpatrick and Kirkpatrick, 2006). We applied the capacity, change and performance model of Baser and Morgan (2008) as a framework and identified indicators based on Mizrahi (2004) (see Sect. 2.2). The selected indicators addressed capacity (working experience, familiarity with three knowledge areas - Mekong Agreement 1995, Conflict management approaches, Technical tools - before and after programme) and change (usefulness of knowledge, application of knowledge, factors hampering application, and change in function in the organisation and opportunities in work) (Table 2). We did not address performance (Sect. 3.3). We realise that to obtain a full picture of capacity, change in behavior, and ultimately performance, a more in-depth data collection and analysis would be needed. We are, however, confident that the array of indicators assessed by a representative response group gives us adequate information to answer the questions posed related to the impact of the MRCFMMP Capacity Building Programme and its design, and provides us with better insights on the conditions needed for change and performance.

The post-training survey was carried out by means of an online questionnaire. By email all mid-level professionals participating in both programme phases were invited to fill out the questionnaire. The questionnaire was online between 15 September and 15 October 2011, which was two years after the end of Phase 1 of the programme, and 5 months after the end of Phase 2. Of the total 63 participants invited (for which we had email addresses), 37 participants responded (Table 3), resulting in a response rate of $58 \%$. The bench 
Table 1. Knowledge areas and subjects taught in the different training modules of the MRC-FMMP Capacity Building Programme.

\begin{tabular}{|c|c|c|}
\hline $\begin{array}{l}\text { Knowledge areas } \\
\text { (and subjects) }\end{array}$ & Training modules & Training methods \\
\hline $\begin{array}{l}\text { Introduction Mekong } \\
\qquad \begin{array}{l}\text { - Integrated water resources } \\
\text { management } \\
\text { - Flood risk management } \\
\text { - Transboundary flood issues } \\
\text { - International cooperation }\end{array}\end{array}$ & $\begin{array}{l}\text { Training Workshop } 1 \\
\text { "Water Resources } \\
\text { Development and } \\
\text { Flood Management in } \\
\text { a Transboundary } \\
\text { Context" (Month 1; } \\
\text { duration } 5 \text { days) }\end{array}$ & $\begin{array}{l}\text { - } \text { Lecture } \\
\text { - } \text { Case studies } \\
\quad \text { (international and local) } \\
\text { - Exercises } \\
\text { - } \text { Role plays } \\
\text { - Discussion } \\
\text { - } \text { Field visits }\end{array}$ \\
\hline $\begin{array}{l}\text { Mekong Agreement } 1995 \\
\text { - International water law } \\
\text { - Mekong Agreement } 1995 \\
\text { - Framework of addressing } \\
\quad \text { and resolving transboundary } \\
\quad \text { issues }\end{array}$ & $\begin{array}{l}\text { Training Workshop } 2 \\
\text { "Transboundary Water } \\
\text { Conflict Management } \\
\text { and International } \\
\text { Water Governance" } \\
\text { (Month 3; duration } 5 \text { days) }\end{array}$ & \\
\hline $\begin{array}{l}\text { Conflict management } \\
\text { - Conflict prevention } \\
\text { - Conflict resolution } \\
\text { - Alternative dispute resolution }\end{array}$ & & \\
\hline $\begin{array}{l}\text { Technical tools } \\
\text { - Model and decision support } \\
\text { systems } \\
\text { - MRC decision support } \\
\text { framework (DSF) } \\
\text { - Impact assessment methods } \\
\text { (environment, economic, } \\
\text { social) } \\
\text { - Strength-Weakness-Opportunity- } \\
\text { Threats (SWOT) } \\
\text { - Role technical tools in } \\
\text { addressing transboundary } \\
\text { issues }\end{array}$ & $\begin{array}{l}\text { Training Workshop } 3 \\
\text { "Technical Tools to Address } \\
\text { Transboundary Issues" } \\
\text { (Month 6; duration } 5 \text { days) }\end{array}$ & \\
\hline All above & $\begin{array}{l}\text { Shariva Pilot Study } \\
\text { (Month 9; duration } 3 \text { days) }\end{array}$ & $\begin{array}{l}\text { - Role play addressing and } \\
\text { resolving imaginary } \\
\text { transboundary issues }\end{array}$ \\
\hline
\end{tabular}


Table 2. Indicators assessed in the post-training survey.

\begin{tabular}{|c|c|c|}
\hline & Indicator & Related to \\
\hline \multirow[t]{2}{*}{$\begin{array}{l}\text { Capacity } \\
\text { enhancement }\end{array}$} & Working experience & $\begin{array}{l}\text { - Water and flood management } \\
\text { - Transboundary water and flood management } \\
\text { - Mekong River Commission }\end{array}$ \\
\hline & $\begin{array}{l}\text { Familiarity with knowledge areas in relation } \\
\text { to addressing and resolving } \\
\text { transboundary issues (before and after } \\
\text { programme) }\end{array}$ & $\begin{array}{l}\text { - Mekong Agreement } 1995 \\
\text { - Conflict management approaches } \\
\text { - Technical tools }\end{array}$ \\
\hline \multirow[t]{3}{*}{ Change in behavior } & Usefulness of knowledge & $\begin{array}{l}\text { - General knowledge } \\
\text { - Specific skills }\end{array}$ \\
\hline & Application of knowledge & $\begin{array}{l}\text { - Individual subjects taught } \\
\text { - Application methods } \\
\text { - Factors hampering application }\end{array}$ \\
\hline & $\begin{array}{l}\text { Change in function in the organisation } \\
\text { and/or opportunities in work }\end{array}$ & (open question) \\
\hline
\end{tabular}

mark for response rates of Internet surveys is $30 \%$ (The University of Texas at Austin, 2007; Sheehan, 2001). The 37 respondents represent $43 \%$ of the total 86 mid-level professionals that participated in both phases of the programme. The response data shows that most of the respondents worked for various government ministries and departments (25 out of the 37 respondents), like water resources, foreign affairs, natural resources and environment and fisheries, followed by training and education institutes (10), and the MRC (5) ${ }^{6}$. The survey population presents a good representation of the total group of participants.

\section{Results of the post-training evaluation}

\subsection{Capacity enhancement}

\subsubsection{Working experience in related areas}

A large part $(65 \%)$ of the 37 respondents worked for 5 years or longer for their employer (Fig. 2). Their working experiences in water and flood management, in transboundary water and flood management, and with the MRC were shorter (between $27 \%$ and $40 \%$ of the respondents for $5 \mathrm{yr}$ or longer), with least experience in transboundary issues of water and flood management (32\% of the respondents had less than $1 \mathrm{yr}$, and no respondents more than $10 \mathrm{yr}$ experience). The MRC-FMMP Capacity Building Programme, therefore, recruited participants with little or no experience in addressing and resolving transboundary issues.

Looking at the differences between the organisations, the data shows that most of the Mekong River Commission

\footnotetext{
$6_{2}$ respondents indicated working for both the MRC and a government department, one respondent worked for both a government department and training and education institute.
}

Table 3. Mid-level professionals participating in Phase 1 and 2 of the MRC-FMMP Capacity Building Programme.

\begin{tabular}{lcccc}
\hline Phase & Government & $\begin{array}{c}\text { Training/ } \\
\text { education } \\
\text { institutes }\end{array}$ & $\begin{array}{c}\text { Total } \\
\text { participants }\end{array}$ & $\begin{array}{c}\text { Survey } \\
\text { response }\end{array}$ \\
\hline Phase 1 & 27 & 8 & 35 & 20 \\
Phase 2 & 37 & $10^{*}$ & $47^{*}$ & $23^{*}$ \\
\hline Total & 64 & 12 & 86 & 37 \\
\hline 6 same as in Phase 1. & & & & \\
\hline
\end{tabular}

respondents had more than five years working experience in water and flood management, in contrast to the majority of the respondents from the training and education institutes, who had little experience in this area. Most Mekong River Commission respondents had more than five years working experience with the Mekong River Commission, while only a few of the respondents from the training and education institutes had worked with the Mekong River Commission. The latter can be partly explained by the fact that relations between the training and education institutions and the Mekong River Commission, at least in the past, were limited. In addition, university curricula on water and environmental sciences only to a limited extent pay attention to transboundary aspects (MRC-FMMP, 2008).

\subsubsection{Familiarity with the knowledge areas addressed}

Respondents were asked to respond to statements related to their familiarity with the three knowledge areas before and after the MRC-FMMP Capacity Building Programme. The knowledge areas assessed were "Mekong Agreement 1995", "Conflict management approaches", and "Technical tools", all three in relation to addressing transboundary issues. The 


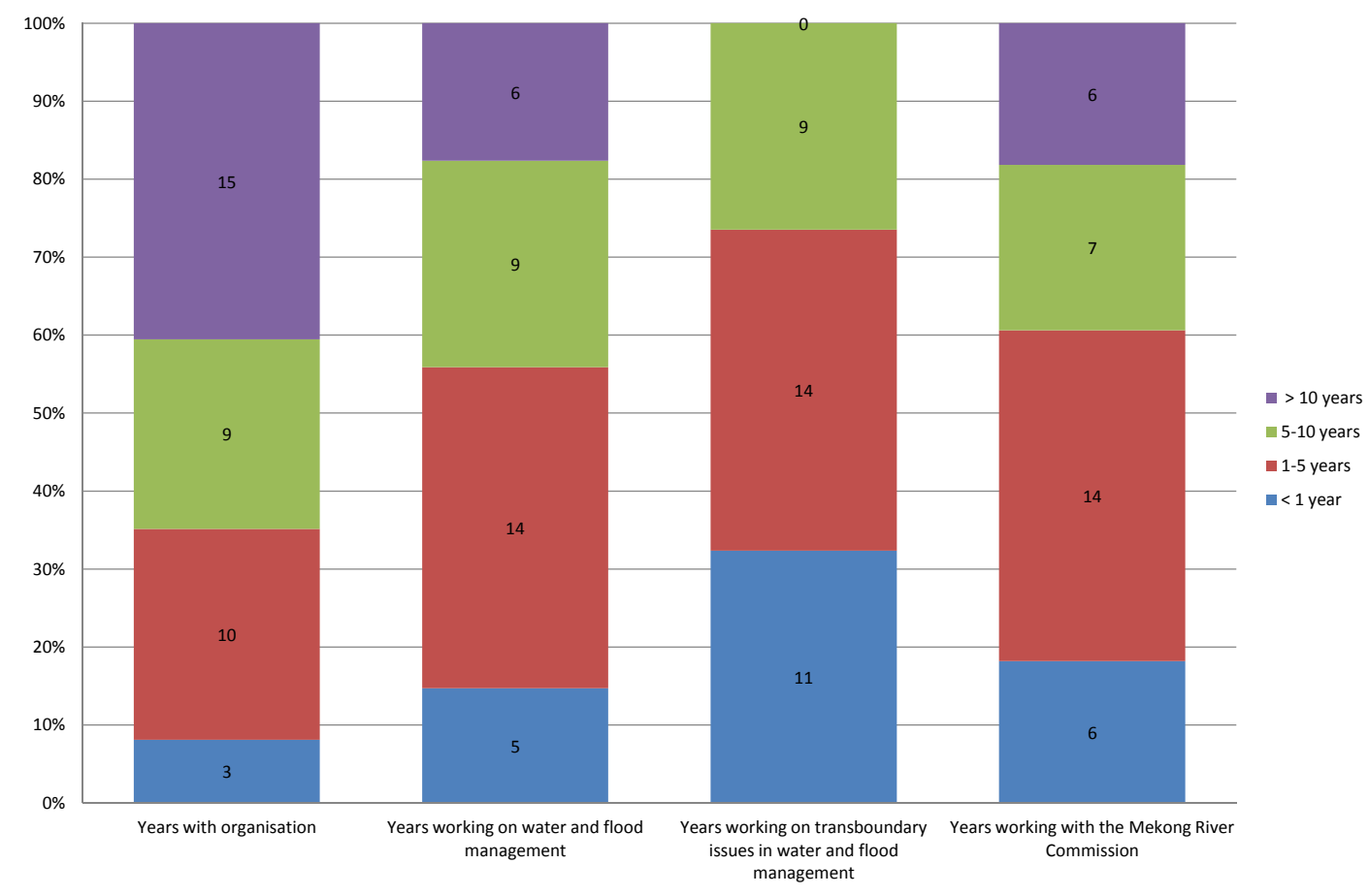

Fig. 2. Years of working experience of respondents $(n=37)$.

data shows that amongst the three knowledge areas, the familiarity before the MRC-FMMP Capacity Building Programme with "Conflict management approaches" was lowest (33\% of the 37 respondents agreed and strongly agreed), and familiarity with the "Mekong Agreement 1995" highest (54\% of respondents agreed and strongly agreed) (see the Supplement). This confirms that "Conflict management approaches" was a relatively new knowledge area for most respondents. Overall, the respondents indicated that the MRCFMMP Capacity Building Programme had led to a substantial increase in their familiarity with the three areas (on average an increase from 3.3 to 4.3; Table 4). Although the familiarity after the MRC-FMMP Capacity Building Programme in both phases was comparable, the increase in familiarity was slightly higher after Phase 2 (increase of 1.3) compared to after Phase 1 (increase between 0.4 and 1.0) (Table 4).

The familiarity with the three knowledge areas before the MRC-FMMP Capacity Building Programme was largest for the respondents from the Mekong River Commission, while the familiarity after the MRC-FMMP Capacity Building Programme was more or less equal when comparing respondents of the different organisations (Table 5). The different starting positions of the respondents, per organisation, are understandable given the mandates and activities of these organisations. The increase in familiarity was largest amongst respondents of training and education institutes, for instance the familiarity with the "Mekong Agreement 1995" increased from 3.0 to 4.2, and with "Conflict management approaches" from 3.0 to 4.4. Respondents from the training and education institutes, although having a different starting position, indicated having gained the most from the MRC-FMMP Capacity Building Programme.

Comparison of the responses about familiarity with the knowledge areas taught with the data on working experience clearly shows that the more working experience the respondents had, the more familiar they were with the knowledge areas after the MRC-FMMP Capacity Building Programme (Table 6). The familiarity before the MRC Capacity Building Programme was clearly lower for the respondents with less than $1 \mathrm{yr}$ experience compared to respondents with more experience, but their increase in familiarity was largest (ranging from 1.3 to 2 ).

\subsection{Change in behavior}

\subsubsection{Usefulness of knowledge addressed}

Almost $95 \%$ of the respondents (strongly) agreed that the knowledge gained during the MRC-FMMP Capacity Building Programme was useful for their professional work. The data shows that the longer the working experience of the respondents, the higher the agreement with the usefulness of the knowledge gained (Table 7). The reason for this result could be that more experienced respondents rank importance of the knowledge gained higher than less experienced respondents; also, they might see more possibilities for applying the knowledge gained than less experienced respondents. The usefulness of the knowledge gained is also illustrated by some of the quotes of the respondents: 
Table 4. Familiarity with three knowledge areas taught in relation to addressing transboundary issues before and after the MRC-FMMP Capacity Building Programme, per phase $(n=37)^{*}$.

\begin{tabular}{lcc}
\hline Knowledge areas & Familiarity before & Familiarity after \\
\cline { 2 - 3 } Phase 1 & Mekong Agreement 1995 \\
Phase 2 & 3.7 & 4.1 \\
\hline Average & 3.2 & 4.5 \\
\hline & 3.4 & 4.3 \\
\cline { 2 - 2 } Phase 1 & Conflict management approaches \\
Phase 2 & 3.5 & 4.1 \\
\hline Average & 3.9 & 4.5 \\
\hline & \multicolumn{2}{c}{ Technical tools } \\
Phase 1 & 3.2 & 4.3 \\
Phase 2 & 3.0 & 4.3 \\
\hline Average & 3.1 & 4.2 \\
\hline *Average score on scale from 1 to 5; 1 = Strongly disagree, 2 = Disagree, \\
3= Neutral, 4= Agree, $5=$ Strongly agree.
\end{tabular}

Table 5. Familiarity with the three knowledge areas taught in relation to addressing transboundary issues before and after the MRCFMMP Capacity Building Programme, per organisation $(n=37)^{*}$.

\begin{tabular}{lcc}
\hline Organisation & Familiarity before & Familiarity after \\
\hline \multirow{2}{*}{ Mekong River Commission } & \multicolumn{2}{c}{ Mekong Agreement 1995 } \\
\cline { 2 - 3 } Government & 4.0 & 4.6 \\
Training and education institutes & 3.5 & 4.4 \\
& 3.0 & 4.2 \\
\cline { 2 - 3 } Mekong River Commission & Conflict management approaches \\
\cline { 2 - 3 } Government & 3.6 & 4.2 \\
Training and education institutes & 3.3 & 4.3 \\
\hline & 3.0 & 4.4 \\
\cline { 2 - 3 } Mekong River Commission & \multicolumn{2}{c}{ Technical tools } \\
Government & 4.0 & 4.2 \\
Training and education institutes & 3.0 & 4.2 \\
\hline
\end{tabular}

Average score on scale from 1 to $5 ; 1=$ Strongly disagree, $2=$ Disagree, $3=$ Neutral, $4=$ Agree, $5=$ Strongly agree.

- "The knowledge gained is better for the cooperation with other countries."

- "IWRM principles are starting to be applied in Cambodia."

- "As I work in the Ministry of Foreign Affairs, I find the knowledge I have learned in the course very useful for me in my professional work, especially those concerning transboundary conflict management."

- "First, the experience from role play helped me to recognise the real situations. Second, I have recognised that
Table 6. Familiarity with three knowledge areas taught in relation to addressing transboundary issues before and after the MRC-FMMP Capacity Building Programme, per years of working experience $(n=37)^{*}$.

\begin{tabular}{lcc}
\hline Working experience related area & Familiarity before & Familiarity after \\
\hline & \multicolumn{2}{c}{ Mekong Agreement 1995} \\
\cline { 2 - 3 }$<1 \mathrm{yr}$ & 2.7 & 4.0 \\
$1-5 \mathrm{yr}$ & 3.1 & 4.1 \\
$5-10 \mathrm{yr}$ & 3.3 & 4.3 \\
$>10 \mathrm{yr}$ & 3.7 & 4.5 \\
\hline & Conflict management approaches \\
\cline { 2 - 3 }$<1 \mathrm{yr}$ & 2.7 & 4.0 \\
$1-5 \mathrm{yr}$ & 3.0 & 4.1 \\
$5-10 \mathrm{yr}$ & 3.3 & 4.3 \\
$>10 \mathrm{yr}$ & 3.3 & 4.5 \\
\hline & \multicolumn{2}{c}{ Technical tools } \\
$<1 \mathrm{yr}$ & 2.3 & 4.3 \\
$1-5 \mathrm{yr}$ & 2.9 & 3.9 \\
$5-10 \mathrm{yr}$ & 3.1 & 4.1 \\
$>10 \mathrm{yr}$ & 3.5 & 4.5 \\
\hline
\end{tabular}

Average score on scale from 1 to $5 ; 1=$ Strongly disagree, $2=$ Disagree, $3=$ Neutral, $4=$ Agree, $5=$ Strongly agree.

tools are very important to help decision makers to make a good decision."

- "It helps me to be more confident in organising the water related training programmes. It also built up my professional connections with other participants and resource persons."

The specific skills addressed in the MRC-FMMP Capacity Building Programme - critical thinking, cooperation, and building trust - were perceived as very important skills, while critical thinking scored a bit lower (79\% very important and extremely important, against $97 \%$ and $94 \%$ for cooperation and building trust). The respondents from the training and education institutes gave overall the highest scores, except for critical thinking.

\subsubsection{Application of knowledge addressed}

The knowledge areas addressed by the MRC-FMMP Capacity Building Programme were taught by various subjects as indicated in Table 2. In the post-training evaluation, respondents were asked about the use in practice of the specific subjects taught. The two subjects most used in practice were the "Mekong Agreement 1995" (67\% of the 37 respondents) and "integrated water resources management" $(64 \%)$. Respondents indicated using the knowledge gained by applying it in their work (78\%), by informing others (60\%), by using it in lecture and training material (22\%) and by giving a presentation $(19 \%)$. Differences in application between organisations are presented in Table 8 .

The two subjects which were considered useful but least applied were "international water law" $(70 \%)$ and "models 
Table 7. Usefulness of knowledge gained for professional work by years of working experience $(n=37)$.

\begin{tabular}{lccccc}
\hline $\begin{array}{l}\text { Working experience } \\
\text { related area }\end{array}$ & $\begin{array}{c}\text { Strongly } \\
\text { disagree }\end{array}$ & Disagree & Neutral & Agree & $\begin{array}{c}\text { Strongly } \\
\text { agree }\end{array}$ \\
\hline$<1 \mathrm{yr}$ & 0 & 0 & 1 & 2 & 0 \\
$1-5 \mathrm{yr}$ & 0 & 0 & 1 & 6 & 3 \\
$5-10 \mathrm{yr}$ & 0 & 0 & 0 & 8 & 1 \\
\hline$>10 \mathrm{yr}$ & 0 & 0 & 0 & 8 & 7 \\
\hline
\end{tabular}

Table 8. Use of knowledge gained, per organisation type (multiple answers allowed) $(n=37)$.

\begin{tabular}{lccc}
\hline Use of knowledge & $\begin{array}{c}\text { Mekong River } \\
\text { Commission }\end{array}$ & Government & $\begin{array}{c}\text { Training/education } \\
\text { institutes }\end{array}$ \\
\hline Informed others & 2 & 17 & 4 \\
Gave a presentation & 2 & 5 & 1 \\
Applied in work & 4 & 20 & 8 \\
Used in lecture or & 0 & 2 & 6 \\
training material & & & \\
\hline
\end{tabular}

and decision support systems" (61\%). When asked about the factors hampering application, 26 (of the 37) respondents claimed to have had no opportunities to apply, followed by 6 who said it was difficult to apply and 2 who did not know how to apply the knowledge gained. For the "models and decision support systems", the objective of the Capacity Building Programme (see Sect. 3.2) was not to be able to apply the models but to be aware of the available tools for transboundary water management. To actually be able to apply these tools was beyond this Capacity Building Programme. Comparing these results with the working experiences of the respondents, the survey shows that almost all respondents with a working experience of up to $10 \mathrm{yr}$ indicated having no opportunities to apply the knowledge gained, while amongst the group of respondents with a working experience above $10 \mathrm{yr}$ - which is $40 \%$ of the respondents - half of this group indicated having no opportunities and the other half indicated to finding it difficult to apply the knowledge gained from the MRC-FMMP Capacity Building Programme.

\subsubsection{Change in function and/or promotion after MRC-FMMP Capacity Building Programme}

The respondents were asked to indicate whether participation in the MRC-FMMP Capacity Building Programme led to a change in their function in the organisation (horizontal change or vertical change to a higher position) or gave them more opportunities to undertake their work. Table 9 presents some of the quotes given by the respondents.
Table 9. Quotes given on change of function and/or having more opportunities after attending the MRC-FMMP Capacity Building Programme.

\begin{tabular}{ll}
\hline Change in function & More opportunities \\
\hline - "Yes, I will be the focal point & - "Yes, most of the projects \\
for related projects". & related to water have been \\
- "I will be the focal point & given to me after \\
for FMMP-MRC project & attending the capacity \\
implementation". & building programme". \\
- "The knowledge and & - "More experiences to \\
skills gained from CBP & develop and teach courses \\
supported my capacity & related to conflict \\
to be in charge of a & management". \\
new teaching course on & - "I have more \\
conflict management". & opportunities to cooperate \\
- "Yes, I am now the & with other experts". \\
coordinator for the FMMP & \\
(Flood Management and & \\
Mitigation Programme)". & \\
\hline
\end{tabular}

\section{Discussion and conclusions}

\subsection{Limitations of the study}

The post-training evaluation resulted in a survey response of $58 \%$ and a good representation of the participants of the MRC-FMMP Capacity Building Programme (43\%; Sect. 3.3). Before discussing the results in the next section, we will first reflect on some of the limitations of the study. A first limitation is related to the fact that we asked respondents to self evaluate their (un)familiarity with certain topics after some period, which most probably will have lead to some bias. Measuring improvement in ability before and after training using self-assessment is difficult because scores are subjective - some participants may grade themselves relatively high and some relatively low - and respondents may tend to over-estimate their abilities. After following a training programme various participants may realise that they actually had lower competence than they initially believed before receiving the training. The results could also be biased by sociocultural factors. The fact that no respondents indicated to be not familiar with the subjects taught after the MRC-FMMP Capacity Building Programme could be because of politeness and not wanting to lose face. The latter could also have been an issue because of the senior level of the participants ( $65 \%$ with a working experience over $5 \mathrm{yr}$ ).

\subsection{Design of the MRC-FMMP Capacity Building Programme and its impact}

We will first discuss the aspects of capacity enhancement assessed in the study: working experience and familiarity with three knowledge areas before and after MRC-FMMP Capacity Building Programme. The majority of the respondents 
were quite senior (working for their organisation over $5 \mathrm{yr}$ ), but working experience in the three knowledge areas assessed was much less, in particular for the respondents of training and education institutes. The results of the posttraining evaluation show that the participants appreciated the MRC-FMMP Capacity Building Programme both in terms of knowledge gained and skills acquired, and that this increased their capacity to address and resolve transboundary issues. Overall, a substantial increase in familiarity was measured after the MRC-FMMP Capacity Building Programme. The largest increase in familiarity was measured by the respondents with limited working experience and those from training and education institutes, as they were least familiar with MRC and MRC-related subjects before attending the MRC-FMMP Capacity Building Programme. The results imply that the design of the MRC-FMMP Capacity Building Programme in terms of objectives and modules addressing a mix of competencies was effective. The results also showed slightly higher familiarity levels after the second phase of the MRC-FMMP Capacity Building Programme, and clearly a large increase in familiarity overall (lower levels before and higher levels after). This gives indications that the gradual development and updating of the MRC-FMMP Capacity Building Programme based on regular evaluations was effective. The gradual development allowed for an update of the curriculum and training material based on the evaluations. Moreover, in the second phase, the Pilot Study was introduced as a module at the end of the MRC-FMMP Capacity Building Programme to give participants the opportunity to apply all knowledge acquired in one - imaginary - case.

We measured "change" by several indicators relating to usefulness of knowledge addressed, application of knowledge, factors hampering application, and change in function in the organisation and opportunities in work. Almost $95 \%$ of the respondents (strongly) agreed that the knowledge gained during the MRC-FMMP Capacity Building Programme was useful for their professional work. The longer the working experience of the respondent the higher this usefulness was rated, as more senior participants, given their longer working experience, probably could better oversee possibilities of using new knowledge. Also, specific skills addressed like building trust and cooperation were seen as very relevant. Practical application, as shown by the responses, however, proved to be more difficult. Most respondents indicated having applied knowledge gained and shared the information with colleagues. At the same time, many respondents indicated that they also faced challenges in applying knowledge gained, whereby a lack of opportunities to apply this knowledge was mentioned the most. Also, respondents indicated that their familiarity had increased, but they required a much longer time to be able to apply the gained knowledge about technical tools and their role in addressing transboundary issues in their work environment. This calls for a capacity building approach in which training workshops and on-thejob training are integrated.
Like Baser and Morgan (2008) argue, the results show that the interrelations between capacity and change are complex and need to be seen in relationship to the context within which they take place, e.g. motivation of participants and possibilities to apply knowledge gained. The results also show the relevance of linking individual capacity to other levels of capacity building (Sect. 2). The MRC-FMMP Capacity Building Programme focused on the individual staff level, with limited relation to the other two levels: enabling environment and organisational level. This is also very challenging. A good way forward would be to better integrate these capacity building activities in the Integrated Capacity Building Programme of the Mekong River Commission and a stronger involvement of national and regional training and education institutes.

An important aspect in the design of the MRC-FMMP Capacity Building Programme was the involvement of national and regional training and education institutes. A selection of institutes was involved from the beginning and the same group of lecturers participated in both phases. The data shows that their familiarity with the subjects of addressing and resolving transboundary issues increased the most compared to the other groups. This had two positive effects. The first effect was that the lecturers, through their intensive involvement in the MRC-FMMP Capacity Building Programme, could play an incremental role in facilitation and lecturing. This effect appeared to be important as not all participants participated in all training modules of the MRCFMMP Capacity Building Programme. In practice, having a few participants as a core group throughout the MRC-FMMP Capacity Building Programme, in our case the lecturers from training and education institutes, proved to be instrumental, as they could support and guide the new participants (internal learning). A second effect relates to the use of the knowledge gained, which was relatively high for the university respondents as we saw above, and which adds to the local ownership and embedding of curriculum developed.

\subsection{Next steps in the MRC capacity building}

The curriculum and training material developed in the MRC-FMMP Capacity Building Programme and experiences gained are useful for the design and implementation of Phase 3. In this phase, the lecturers who participated in the first two phases of the MRC-FMMP Capacity Building Programme will adjust the curriculum and will be responsible for implementation at the national levels (short courses for high-level decision makers and mid-level professionals, university curriculum). As teaching capacities vary and competencies to teach certain knowledge areas are still lacking, a number of approaches are considered in overcoming this. These include training and education institutes supporting each other, introducing guest lecturers from water sector organisations like the MRC and national line agencies, 
and continued capacity building like training of trainers and coaching to address teaching gaps.

The MRC-FMMP Capacity Building Programme focused on addressing and resolving transboundary flood issues. The experiences gained are useful in broadening the capacity building scope to all water and water-related transboundary issues in the Mekong River Basin. At the moment the MRC is engaged in the development of a module-based IWRM competency framework. This framework aims to address the competency gaps in implementing IWRM policies and MRC procedures and related technical guidelines in the Mekong River Basin in a systematic way. The experience gained in the MRC-FMMP Capacity Building Programme provides important input to the development of this framework.

\subsection{Reflection on design and implementation of MRC-FMMP Capacity Building Programme}

The design of the MRC-FMMP Capacity Building Programme well reflected the components of addressing and resolving transboundary flood issues. We realise that the Capacity Building Programme, basically consisting of 4 oneweek trainings, can only achieve limited results in terms of capacity enhancement. Offering assignments and reading materials in between the training modules could be a more structured way to enhance the cumulative learning experience. Phase 1 really lacked the integrative component which was added in Phase 2 through the Pilot Study, and this was a very useful addition to the Capacity Building Programme.

The unfortunate part was that the composition of the participants for each phase was not consistent; the original idea of having one fixed group following the entire programme was not implemented as such, and this created a discrepancy between the participants in their cumulative knowledge. The interaction between mid-level professionals from different countries and training and education institutes proved to be very beneficial in at least partly overcoming these discrepancies. To create the best environment for learning, the group should remain constant as much as possible and follow the entire programme.

In our opinion the mixture of participants with a varying range of years of working experience was beneficial to the overall learning experience, as participants with more working experience could relate the knowledge areas to practical experience in the field and share it with the group. Not surprising, the group with less working experience indicated a higher level of increase in familiarity with the knowledge areas.

The current target group for the MRC-FMMP Capacity Building Programme is members from the MRC member countries, although a few participants from Myanmar and China participated in parts of the programme. For basinwide cooperation, the Capacity Building Programme should be extended to include participants from the two upstream countries, including participants from training and education institutes. The content of the Capacity Building Programme can remain the same as all knowledge areas relevant to basinwide cooperation are covered.

The next phase of the MRC-FMMP Capacity Building Programme is mainly focused on the national curricula and short course delivery. This will contribute to the capacity development in the individual countries as the local language can be used and a larger number of professionals working within the Mekong region can be reached. However, these trainings tend to focus more on the national perspective and the transboundary element is reduced. Regional trainings will remain to be required in order to maintain the overall spirit of transboundary cooperation between the MRC member countries.

\subsection{Recommendations for the design of similar capacity building programmes}

The results lead into the following six recommendations for the design of similar capacity building programmes.

- Selection of the right group of participants is crucial for the success of a capacity building programme. Selection criteria related to relevance of the topics for the participants and their work/organisation is essential. Moreover, the subject of addressing and resolving transboundary issues does not only require water professionals but a mix of professionals and institutions to participate in a capacity building programme.

- The subject of addressing and resolving transboundary issues is complex and requires a mix of competencies to be addressed. Professionals involved with specific backgrounds need to be educated into team members who understand each other's background and can work in multi-disciplinary teams. This requires addressing different aspects, including physical, legal, technical, social, economic and political aspects, and a strong focus on the integrative nature of transboundary issues, which can be supported by training modalities like case studies and role plays representing real life situations.

- The complexity of the subject area, and in many situations its innovative character, requires the gradual development of a capacity building programme capable of learning and being updated. Post-training evaluation is part of this process. Such an approach may seem and may be more expensive, but in the end it will result in a higher quality programme with stronger regional embedding.

- Involvement of national and regional training and education institutes like universities is important for embedding the capacity building efforts. These institutes should work closely with water and water-related sector organisations, like the national line agencies and river basin organisations, in capacity building. 
- A successful capacity building programme needs to address the three levels of capacity building (enabling environment, organisations, and individual staff). Capacity building strategies at river basin level should address these different levels taking contextual factors, like culture and local language, into account.

\section{Supplementary material related to this article is available online at: http://www.hydrol-earth-syst-sci.net/ 16/3183/2012/hess-16-3183-2012-supplement.pdf.}

Acknowledgements. The work presented is based on the evaluation of the Capacity Building Programme of the Mekong River Commission, Flood Management and Mitigation Programme (MRC-FMMP), Component \#3 "Enhancing cooperation in addressing transboundary flood issues". The Capacity Building Programme is implemented by UNESCO-IHE, UNESCO-PCCP, Rado International and Deltares together with the following national and regional training and education institutes: Royal University of Phnom Penh, National University of Laos, Mekong Institute (Thailand), King Prajadhipok's Institute (Thailand), and the Hanoi Water Resources University. The Capacity Building Programme is funded by MRC-FMMP. The project was co-funded by the Netherlands Ministry of Development Cooperation (DGIS) through the UNESCO-IHE Programmatic Cooperation Fund.

Edited by: S. Uhlenbrook

\section{References}

Alaerts, G. and Kaspersma, J.: Progress and challenges in knowledge and capacity development. Chapter 1, edited by: Blokland, M. W., Alaerts, G. J., Kaspersma, J. M., and Hare, M., Capacity Development for improved water management, Delft: Taylor and Francis, 3-28, 2009.

Baran, E., Starr, P., and Kura, Y.: Influence of built structures on Tonle Sap fisheries. Cambodia National Mekong Committee and the WorldFish Center, Phnom Penh, Cambodia, 2007.

Baser, H. and Morgan, P.: Capacity, Change and Performance Study Report, Discussion Paper No. 59B, European Centre for Development Policy Management, 2008.

Bearden, B. L.: The legal regime of the Mekong River: a look back and some proposals for the way ahead, Water Policy, 12, 798821, 2010.

Cap-Net: Capacity Building for Integrated Water Resources Management; The importance of Local Ownership, Partnerships and Demand Responsiveness, Cap-Net, 8 pp., available at: http://cap-net.org/sites/cap-net.org/files/ CapacitybuildingforIWRM3principles.pdf, 2002.

Cheetham, G. and Chivers, G.: Towards a holistic model of professional competence, Journal of European Industrial Training, 20, 20-30, 1996.

Chheang, V.: Environmental and economic cooperation in the Mekong region, Asia Eur. J., 8, 359-368, 2010.
Douven, W. J. A. M., Douben, K. J., Goichot, M., Ngoc, H. M., van der Ruyt, M., and Verheij, H. J.: Roads and Floods: Towards improved guidelines for road development and reconstruction in the Mekong floodplains of Cambodia and Vietnam, $5^{\text {th }}$ Annual Mekong Flood Forum, Regional Flood Management and Mitigation Centre, Phnom Penh, Cambodia, 2007.

Earle, A., Martinsen, C., Qwist-Hoffmann, P., Sandström, K., Malzbender, D., and Kariuki, J.: Capacity building programmes for effective transboundary water management. Proceedings of 13th IWRA World Water Congress 2008, 1-4 September 2008, Montpellier, France, available at: http://www.iwra.org/ congress/2008/resource/authors/abs690_article.pdf (last access: 1 July 2012), 2008.

Fox, C. A. and Sneddon, C.: Transboundary river basin agreements in the Mekong and Zambezi basins: enhancing environmental security or securitizing the environment?, Int. Environ. Agreem., 7, 237-261, 2007.

Jonker, L., Van der Zaag, P., Gumbo, B., Rockström, J., Love, D., and Savenije, H. H. G.: Why a regional approach to postgraduate water education makes sense - the WaterNet experience in Southern Africa, Hydrol. Earth Syst. Sci. Discuss., 9, 35813606, doi:10.5194/hessd-9-3581-2012, 2012.

Kaplan, A.: The Core of our Work as Capacity Builders, Annual Report, CDRA, 2007.

Kirkpatrick, D. L. and Kirkpatrick, J. D.: Evaluating Training Programs, Berrett-Koehler, 3rd Edn., 2006.

Mizrahi, Y.: Capacity enhancement indicators, WBI Working Papers, The World Bank, Washington DC, 2004.

MRC: Agreement on the cooperation for the sustainable development of the Mekong River Basin, 1995.

MRC: Procedures for Notification, Prior Consultation and Agreement, 2003.

MRC: Integrated Capacity Building Programme, Programme Document, 2009.

MRC: State of the Basin Report 2010, Mekong River Commission, Vientiane, Lao PDR, 2010.

MRC: Prior Consultation Project Review Report, Proposed Xayaburi Dam Project - Mekong River, 2011.

MRC-FMMP: Transboundary Flood Issue Identification, 2007.

MRC-FMMP: Implementation Plan, Capacity Building Programme of the Mekong River Commission Flood Management and Mitigation Programme-Component 3 "Anticipating and resolving flood issues, differences and disputes in the Lower Mekong Basin", Version 18 December 2008, Vientiane, Lao PDR, 2008.

MRC-FMMP: Annual Mekong Flood Report, 2008, 2009a.

MRC-FMMP: Explanatory Note-Supporting Document to the Working Paper On The Legal Aspects of the Mandate of the 1995 Mekong Agreement For Enhancing Cooperation in Addressing Transboundary Flood and Related Issues, 2009b.

MRC-FMMP: Flood assessment report 2011 floods, Phnom Penh, Cambodia, 2011.

MRC-FMMP: Design and Implementation of the Pilot Study for Addressing and Resolving Transboundary Flood Issues, Technical Report MRC FMMP-Component 3, 2012.

OECD-DAC: DAC Network on Governance, The Challenge of Capacity Development: Working towards Good Practice, available at: http://siteresources.worldbank.org/INTCDRC/ Resources/oecd_challenge_of_capacity_development.pdf (last access: 1 July 2012), 2006. 
Pahl-Wostl, C., Sendzimir, J., Jeffrey, P., Aerts, J., Berkamp, G., and and Cross, K.: Managing change toward adaptive water management through social learning, Ecol. Soc., 12, 30, available at: http://www.ecologyandsociety.org/vol12/iss2/art30/, 2007.

Poulsen, A. F., Poeu, O., Viravong, S., Suntornratnana, U., and Tung, N. T.: Fish migrations of the Lower Mekong Basin: Implications for development, planning and environmental management, MRC technical paper No. 8, Phnom Penh: MRC, 2002.

Savenije, H. H. G. and Hoekstra, A. Y.: Water Resources Management, in: Knowledge for sustainable development: An insight into the encyclopedia of life support systems, Volume II, UNESCO publishing/EOLSS Publishers, 2003.

Sheehan, K.: E-mail survey response rates: a review, J. Comput.Mediat. Comm., available at: http://jcmc.indiana.edu/vol6/ issue2/sheehan.html (last access: 1 July 2012), 2001.

Sneddon, C. and Fox, C. A.: Rethinking transboundary waters: A critical hydropolitics of the Mekong basin, Polit. Geogr., 25, 181-202, 2006.

Uhlenbrook, S. and de Jong, E.: T-shaped competency profile for water professionals of the future, Hydrol. Earth Syst. Sci. Discuss., 9, 2935-2957, doi:10.5194/hessd-9-2935-2012, 2012.
UNDP: UNDP Capacity Assessment Practice Note, United Nations Development Programme, 30 pp., 2008.

UNESCO: Water security and peace: A synthesis of studies prepared under the PCCP-Water for Peace process, compiled by: Cosgrove, W. J., PCCP series No. 29, Paris, 2003.

UNESCO-WWAP: World Water Development Report 2: Water, a shared responsibility, UNESCO, Paris, 2006.

The University of Texas at Austin: Instructional Assessment Resources, Response rates, available at: http://www.utexas.edu/academic/ctl/assessment/iar/teaching/ gather/method/survey-Response.php (last access: 7 November 2011), 2007.

Van der Zaag, P., Bos, A., Odendaal, A., and Savenije, H.: Educating Water for Peace: the new water managers as first-line conflict preventors, Paper prepared for the UNESCO-Green Cross "From Potential Conflict to Cooperation Potential: Water for Peace" sessions; 3rd World Water Forum, Shiga, Japan, 20-21 March 2003. 